\title{
1.2. Las migraciones españolas al extranjero
}

\author{
"Hay circunstancias en las que el criterio puesto \\ en práctica es el de exigix del trabajador el máximo \\ rendimiento posible, cuando es un emigrante, sin \\ preoemparse de su personay (Juan Pablo \\ jico).
}

\section{DESCRIPCION GENERAL}

\subsection{PROBLEMA ACTUAL}

El hecho cierto de que ya no se da la emigración masiva de españoles para trabajar y establecerse en otros países, tanto de Europa como de ultramar, puede hacer pensar que las migraciones al extranjero han dejado de ser un grave problema para la comunidad española.

Ciertamente los problemas no son los mismos hoy que durante los años 60 , cuando los emigrantes eran unos «recién llegados» a países desconocidos, sin ninguna preparación y en una situación de total desamparo. Solamente hacia Europa salieron con contrato de trabajo 1.175 .000 españoles entre 1960 y 1970 . Entonces se trataba de sobrevivir aceptando cualquier trabajo y cualquier condición de salario y de vivienda. Las familias muchas veces quedaban separadas antes de conseguir las condiciones para la reagrupación familiar. Sucede siempre que los emigrantes últimos en llegar tienen que aceptar los peores puestos en el campo laboral y social.

Hoy día, los emigrantes españoles llevan ya, en general, bastantes años en los países donde trabajan. Han conseguido una relativa promoción y otros emigrantes han venido a ocupar los puestos más bajos en la escala social. Han conseguido algunas de las metas de tipo econónico que se habían propuesto. Se han organizado y han luchado por la reivindicación de algunos derechos sociales y culturales.

Sin embargo, muchos de los problemas permanecen y algunos incluso se agravan: inseguridad ante el futuro, xenofobia, desarraigo, porvenir de los hijos, etc. 
La emigración española no es un fenómeno reciente. Ya en el período 1901-1915 se cifraban en 1.701.395 los emigrantes españoles. Sin em. bargo, sí es teciente un cambio fundamental en la dirección de la emigración. Esta, que hasta los años 50 se dirigía principalmente hacia His" panoamérica, comienza entonces a dirigirse a Europa: monedas fuertes y menos de cuarenta y ocho horas de distancia de la tierra abandonada, con la posibilidad de volver en automóvil, siempre signo de éxito y progreso, al pueblo de que se partiera.

Actualmente, los retornos son más numerosos que las salidas. Según el informe del Banco de Vizcaya y en el período $1973-78$ retornaron 450.000 emigrantes. Solamente en Alemania Federal, durante el mismo período regresaron 146.000 .

Sin embargo, las cifras de tesidentes en el extranjero no han disminuido en la misma proporción. Se debe, no a la salida de nuevos etmigrantes, sino al crecimiento demográfico y a la reagrupación familiar.

Las cifras que se dan actualmente y de una forma global son de tres millones de emigrantes españoles. Un millón de ellos en Europa y dos millones en el resto del mundo, la mayor parte en América Latina.

En este trabajo nos ocuparemos exclusivamente de los emigrantes en Europa. Sería muy complejo el tratar al mismo tiempo las migraciones a ultramar, ya que tienen características y problemas muy distintos.

\section{Emigrantes españoles en Europa en 1978}

\begin{tabular}{|c|c|c|}
\hline & TRABAYADORES & RESIDENTES \\
\hline Austria $\ldots \ldots \ldots \ldots \ldots$ & - & $723(1)$ \\
\hline Bélgica $\ldots \ldots \ldots \ldots \ldots$ & 27.000 & 64.500 \\
\hline Dinamarca $\ldots \ldots \ldots \ldots$ & - & 745 \\
\hline Francia $\ldots \ldots \ldots \ldots$ & 184.500 & 507.300 \\
\hline Gran Bretaña ......... & - & $55.000(1)$ \\
\hline R.P.A. $\ldots \ldots \ldots \ldots \ldots$ & 95.800 & 188.900 \\
\hline Luxemburgo $\ldots \ldots \ldots$ & - & $2.000(1)$ \\
\hline Molanda $\ldots . . . . . .$. & 17.600 & 34.800 \\
\hline $\begin{array}{llllll}\text { Suecia } & \ldots & \ldots & \ldots & \ldots\end{array}$ & 1.700 & 3.600 \\
\hline $\begin{array}{llllll}\text { Suzza } & \ldots & \ldots & \ldots & \ldots & \ldots\end{array}$ & 61.600 & 96.100 \\
\hline TOTAL $\ldots \ldots$ & & 953.668 \\
\hline
\end{tabular}

Fuente: SOPEMT (Sistema de Observación Pernanente de las Migraciones), OCDE, París, 1979.

(1) Boletín Informativo del Secretariado de la Comisión Episcopal de las Migraciones, núm. 182, eneto-febrero, 1980. 


\subsection{CaUSAS DE: LA EMIGRACIÓN}

Al analizar la problemática migratoria, conviene tecordar que los emigrantes no salieron de su tietra ejerciendo libremente un derecho a emj. grar. Iin realidad fueron empujados por unas circunstancias que no les permitian una vida digna en su país. Un derecho anterior al de poder emigtar es el de poder vivir y trabajar en su propia tierra, atajando las causas que hacen del emigrar no un privilegio, sino una dura realidad.

«Cuando para sobrevivir no queda otra alternativa que emigrar, la tan aireada libertad de emigración se convierte en tapadera de injusticias», denunciaban en carta pastoral de enero de 1973 los Obispos de las provincias eclesiásticas de Andalucía.

\section{Las causas objetivas de la emigración son bien conocidas:}

- $\mathrm{e}$ l crecimiento vegetativo de la población que al final de los años 50 eleva desproporcionadamente el índice de subempleo. El paro en el campo y la no existencia de industrias que absorban la mano de obra excedente.

- La estructura de la propiedad agraria (latifundios en el Sur y Extremadura con paro estacional creciente y minifundios improductivos en Galicia y Centro) y la escasa fertilidad de la tierra, aunados a los bajos salarios agrícolas, que motivan el desplazamiento de los jornaleros hacia zonas industriales de la península primero, y del exterior después.

- El anacronismo de la aldea española con unos deficientes niveles educativos, sociales, alimentarios, culturales y de babitat.

Los mismos emigrantes, a través de una encuesta, expresaban asi los motivos de su emigración:

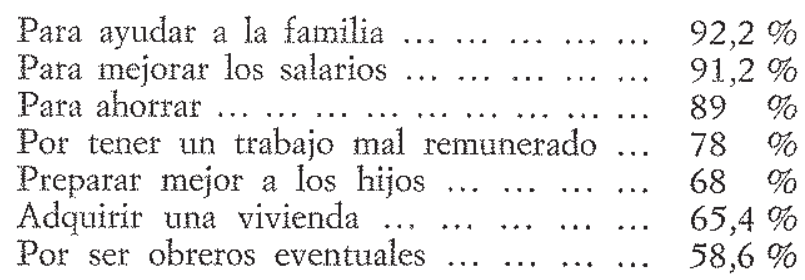

Además de la necesidad y los motivos que cada uno tuvo para salir de su tierra, la emigración ha sido consecuencia de una determinada organización y planificación polútico-económica del país. Los planes de desarrollo contaban con la emigración pata conseguir sus objetivos. En un estudio publicado por el Instituto Español de Emigración (I.E.E.), en 1959 se consideraba que en un período de diecisiete años deberian emigrat un total de 1.472 .000 personas. El contingente anual se fijaba en 
81.350 personas, estimándose el 41 por 100 población activa y el 59 por 100 dependiente.

La sociedad española se vio así aliviada y beneficiada a corto plazo, librándose de un excedente de mano de obra y consiguiendo unos ingresos de divisas que han ayudado durante muchos años, junto con los ingresos por el turismo, a equilibrar la balanza de pagos (1).

Tuvo influencia en la emigración, la propaganda que la pintaba de color de rosa y el aparente éxito de los mismos emigrantes que volvian de vacaciones con coche y dinero, pero silenciando los sufrimientos y los graves costos humanos y familiares que llevaba consigo la emigración.

Se dice que la sociedad española se vio beneficiada a corto plazo, pues a la larga, la emigración supone un empobrecimiento para el país de origen. Pueblos y regiones han quedado con una población envejecida y con pocas posibilidades de desarrollo.

\subsection{POR QUÉ SE LES RECIBÍA}

Los motivos por los que los países de inmigración han recibido a los emigrantes no fueron evidentemente unos motivos humanistas, sino los intereses económicos y las necesidades del mercado de la mano de obra.

(1)

\begin{tabular}{|c|c|c|c|c|c|}
\hline \multirow[b]{3}{*}{1961} & \multirow{2}{*}{$\begin{array}{c}\text { Déficit de la } \\
\text { Balanza } \\
\text { comercial } \\
\text { (millones } \\
\text { de dólates) }\end{array}$} & \multicolumn{4}{|c|}{ Porcentaje cubierto por (En \%) } \\
\hline & & $\begin{array}{c}\text { Turismo } \\
\text { (1) }\end{array}$ & $\begin{array}{l}\text { Rem } \\
\text { emis }\end{array}$ & $\begin{array}{l}\text { as de } \\
\text { antes }\end{array}$ & $\begin{array}{c}\text { [nversiones } \\
\text { extranj. } \\
\text { (2) }\end{array}$ \\
\hline & 278,71 & 118,6 & 4,8 & 41,6 & 68,6 \\
\hline 1962 & 637,85 & 73,0 & 33,1 & 23,2 & 16,8 \\
\hline 1963 & $1.012,63$ & 60,3 & 25,4 & 19,8 & 21,1 \\
\hline 1964 & $1.070,20$ & 79,6 & 29,8 & 22,3 & 25,0 \\
\hline 1965 & $1.758,66$ & $58, \frac{4}{3}$ & 20,6 & 17,1 & 18,3 \\
\hline 1966 & $1.991,70$ & 60,3 & 21,1 & 17,4 & 152 \\
\hline 1967 & $1.781,18$ & 62,3 & 25,4 & 18,3 & 28,2 \\
\hline 1968 & $1.575,20$ & 70,3 & 29,4 & 20,6 & 27,7 \\
\hline 1969 & $1.870,59$ & $63,8^{\circ}$ & 30,0 & 21,5 & 25,7 \\
\hline 1970 & $1.873,74$ & 82,3 & 36,0 & 25,0 & 37,2 \\
\hline 1971 & $1.598,98$ & 117,4 & 50,6 & 34,4 & 37,6 \\
\hline 1972 & $2.316,38$ & 96,3 & 41,1 & 258 & 40,3 \\
\hline 1973 & $3.545,35$ & 812 & 43,5 & 25,8 & 22,8 \\
\hline 1974 & $7.069,09$ & 39,7 & 20,1 & 12,2 & 20,2 \\
\hline
\end{tabular}

Fuente: Elaboración propia a través de datos del Ministerio de Comercio. Balanza de Pagos en España, edición de junio de 1975.

(1) Saldo de ingresos y pagos.

(2) Capital privado a larigo plazo.

(3) Contabilizando también uotras transferencias prívatass.

Cuadro tomado del libro Emigración y desarrollo español, de Santago Mancmo. Editado po: el Ministerio de Trabajo. 
Al mismo tiempo que en España se daba un excedente de mano de obra, en los páses de Centroetropa había una falta de fuerza de trabajo motivada por el crecimiento de la producción y del sector de servicios, la reducción del horario de trabajo, el alargamiento de las vacaciones, el rebajas la edad de retiro, la prolongación de la edad escolar.

En dichos países hacía falta mano de obra que aceptara el ocupar puestos de trabajo mal pagados o socialmente mal considerados, mano de obra más abundante y sumisa que ayudara a rebajar la presión sobre salarios y las condiciones de trabajo.

Esta mano de obra suponía, además, un ahorro para los países teceptores, ya que recibían unas personas preparadas para trabajar, ahorrándose los gastos de formación del trabajador. Según el Instituto Español de Emigración el 85 por 100 de los emigrantes, asistidos en el período 1961-1971, tenían edades comprendidas entre los quince y treinta y nueve años, es decir, estaban en la etapa central de la vida, en la que la capacidad física es mayor.

Esta correspondencia de necesidades entre países receptores y patses emisores (países meditertáneos) hacía de la migración un fenómeno masivo e incontrolado.

Desgraciadamente, las leyes del mercado de mano de obra hacen emigrar a los trabajadores y sus familias, pero no tienen en cuenta unos derechos y necesidades familiares, sociales y culturales. Esos emigrantes tuvieron que hacer frente a graves problemas de desarraigo, de vivienda, de incomunicación, de educación, etc.

\subsection{PAPEI ASTGNADO A LOS EMIGRANTES}

A los emigrantes se les ha asignado en Europa un papel desde su relación exclusiva con la economía. Los aspectos y necesidades familiares, sociales y culturales han quedado siempre relegados.

La emigración se ha podido definir como un sistema general de aprovisionamiento para empleos manuales, no cualificados, peligrosos, insalubres, exigiendo una fuerte movilidad de trabajadores cuyo «costo de preparación’ hasta la edad de producción, corre a cargo de los países de origen y cuyo costo de formación profesional es mínimo o nulo.

El emigrante es pues un trabajador manual, cuya tarea reviste ciertas características: trabajo pesado, largo, en equipos alternos, trabajo precario, mal pagado, con riesgo de accidentes, en un ambiente penoso y reducido exclusivamente a tareas de mera ejecución.

Es también un trabajador interino. Considerado por principio como un obrero de paso, preferentemente aislado, sin familia, destinado a volver a su país de origen apenas cumplido su trabajo. Su presencia, solo 
tolerada, viene reglamentada en función del provecho que se le puede sacar.

Finalmente es un trabajudor extranjero (lo que justifica, en nombre de la ley, es decir, de la nacionalidad, gran númeto de discriminaciones). Se procura la adaptación del inmigrante en la esfera de la producción y del consumismo, pero procurando mantenerlo en la marginación social.

Esta imagen del emigrante, que lo reduce a su sola función económica, hace que el mismo se encuentre a merced de las necesidades del mercado de mano de obra y que pueda ser llamado o rechazado como si se tratara de de una mercancía.

Por esto, un emigrante en situación de paro no tiene sentido, puesto que el emigrante ha emigrado y reside en el país nada más que por el trabajo y para el trabajo.

\subsection{Marginados}

No se puede decir que los trabajadores españoles en Europa estén marginados desde un punto de vista económico. Aunque ocupan generalmente los últimos y peores puestos en la escala laboral, no se puede decir que ganen menos que los nativos de su categotía. Incluso, los emigrantes, por su espíritu de ahorro tienen a veces una situación mejor que muchos obreros del país. Los obreros españoles, a pesar del problema de la vivienda, ya no viven generalmente en barracas, y si algunos lo hacen todavía, puede ser por su interés excesivo de ahorrar y prepararse al retorno.

Sin embargo, los emigrantes están marginados ya por el hecho de estar sometidos a una ley de extranjeros, a unos permisos de trabajo y de residencia que constantemente les recuerda que no están en casa, que son extranjeros, que viven condicionados (permisos, amenazas, restricciones), que no tienen ninguna seguridad en el futuro, sino que viven en precatio.

Están marginados de la convivencia social a causa de la lengua y el desnivel cultural. Están en inferioridad de condiciones en la fábrica y en la vecindad. Difícilmente pueden participar en las asociaciones de todo tipo. Tienen que refugiarse en las asociaciones y centros españoles y están condenados a llevar una vida social de «ghetto».

También la lengua, sobre todo en los países germánicos, y el desnivel cultural marginan a los emigrantes en el campo cultural. Apenas pueden abrirse a la cultura del país. También viven al margen de la evolución social y cultural de su país.

Marginación también politica. Los emigrantes no tienen derecho a ningún voto, ni comunal, ni regional, ni nacional. 


\subsection{INTEGRACIÓN - ASIMMACTÓN - INSERCIÓN}

Hay algún pás, como Alemania, que hasta ahora no ha aceptado ser país de inmigración. Los emigrantes son solamente «trabajadores invitados».

Hay que tener en cuenta, sin embargo, que aunque los españoles salieton con la intención de un retorno lo antes posible, la mayor parte de ellos se han visto obligados a prolongar de año en año su estancia en esos países y muchos se quedarán definitivamente.

Esto obliga a los Gobiernos, a las Institutciones, a la Iglesia, a pensar en la manera de integrar esos grupos y comunidades. Esta integración se ha concebido muchas veces como una asimilación. Los emigrantes deberían despojarse de sus raíces, de su cultura para hacerse alemanes, franceses, etc.

Hoy se habla más, al menos en algunos países, de inserción queriendo subrayar el derecho a ser un verdadero ciudadano que conserva a la vez sus propios valores y cultura.

Esto no se puede conseguir aisladamente sin la posibilidad de formar comunidades étnicas y culturales que vivan y afirmen su propia personalidad. No deberían ser ciertamente comunidades cerradas, sino abiertas y dispuestas a recibir el influjo de la cultura ambiente, a la vez que aportan también sus propios valores.

\subsection{StTUACIÓN RELIGIOSA}

El fenómeno de las migraciones tiene forzosamente una incidencia en la fe y en la práctica religiosa de los emigrantes.

Antes de todo hay que tener en cuenta los siguientes factores:

- Los emigrantes proceden generalmente de tegiones y de capas sociales donde la práctica teligiosa regular no era frecuente.

- Los emigrantes carecían de una formación religiosa adecuada y su religión se confundía a veces con la cultura y forma de vivir de sus lugares de origen.

- Su salida al extranjero tenía, en la intención, un carácter de temporalidad pensando siempre en el tetorno después de conseguit unas metas de tipo económico. Los demás aspectos de la vida, como el religioso, quedaban en segundo plano.

- El poder integrarse en las comunidades locales exige un conocimiento de la lengua y una formación religiosa que los emigrantes no poseen. 
- El encuentro con una cultura extraña: industrial, pluticultural y plurireligiosa supone un choque para las convicciones personales de los emigrantes.

- La formación religiosa de los niños no se da ordinariamente en las escuelas, sino que exige la inscripción y la asistencia regular a la parroquia.

No tenemos datos o estudios generales sobre la práctica y la evolución religiosa de los emigrantes. Sin embargo, la experiencia y el contacto directo muestran que los emigrantes no se integran generalmente en las parroquias y comunidades locales. Su práctica religiosa queda limitada a la petición de los Sacramentos del Bautismo, Matrimonio y Primeras Comuniones, Incluso las Primeras Comuniones para las que se exigen unos años de catecismo son hechas a veces en España, aprovechando las vacaciones, con muy poca preparación.

Las misiones españolas tienen más influencia, allî donde llegan, en la vida religiosa de los emigrantes. El tener unos servicios en su propia lengua y adaptados a su mentalidad hace que los emigrantes puedan participar más fácil y activamente. Muchas veces los misioneros han sido los animadotes de las colonias españolas y alrededor de las misiones se ha realizado una actividad no solamente religiosa sino de tipo social y cultural.

A falta de datos exactos habrá que decir que una mayoría de emigrantes no practica regularmente, limitándose a solicitar los Sacramentos digamos sociales. Hay otto grupo que participa ordinariamente en la vida de la Iglesia, generalmente a través de las misiones españolas.

Y finalmente un grupo minoritario que participa más activamente en grupos de reflexión, movimientos apostólicos, consejos de misión, etc. También hay que decir que la gran mayotía de los emigrantes a pesar de todas las dificultades, conservan fundamentalmente su fe y viven grandes valores evangélicos como solidaridad, espíritu de sacrificio, amor a la familia... Se puede hablar a este respecto de la religiosidad popular de los emigrantes con todo lo positivo y lo ambiguo de esta religiosidad.

\subsection{EMLRACION DETENIDA, PROBLEMÁTTCA ACELERADA}

Este fue el lema de la Tornada del Día de las Migraciones del año 76. Efectivamente, la detención de la emigración, el cierre de las fronteras, significó el crecimiento de los problemas y de la inseguridad de los emigrantes.

A finales de 1973 primeros meses del 74, uno tras otro, todos los países cierran sus puertas a los trabajadotes extranjeros. Desde entonces, siguen prácticamente cerradas esas puertas y con intentos de una más drástica reducción en la población laboral extranjera. 
Especialmente en Francia, se intenta disminuir el riúmero de los inmiorados con incentivos económicos al retorno y con unas proposicones de ley. Aunque haya promesas de que estas leyes no afectarán a los españoles, nadie puede garantizar su no aplicación y el clima que se crea en contra de los emigrantes, afecta por igual a todos ellos. Porque, además de los efectos directos que puedan tener estas leyes, están los efectos indirectos. Los emigrantes quedan señalados como si fueran los causantes de la crisis económica y el paro, siendo como son, las víctimas de los mismos. El racismo y la xenofobia siempre más o menos latentes, son exacerbados por una política que intenta desviar la atención de los verdaderos problemas.

Dos son las causas de esta política anti-inmigratoria:

- La primera es la ya indicada de la coyuntura crítica económico. social con el paro consiguiente. Esta, quizá, es más un pretexto que causa real. Los trabajos realizados por los emigrantes son, en general, trabajos no queridos por los nativos. En todo caso, los emigrantes, que han contribuido con su trabajo al desartollo de la economía de esos países, tendrían que tener derecho a beneficiarse de las prestaciones sociales cuando se encuentran en paro.

- La verdadera causa de esa política puede ser la siguiente:

A finales de los años 60 los emigrantes en Europa comenzaban a presentar graves costos sociales y culturales correspondientes a su inserción en las diversas comunidades nacionales: instalación de familias, escolarización de los niños, viviendas subvencionadas, problemas de la «segunda generación», acceso de los jóvenes inmigrados al trabajo, formación profesional, expresión cultural y asociativa, participación en la vida cívica, constitutción de una sociedad pluriétnica y pluriracial... Estos son los imperativos sociales que quieren justificar la política de bloqueo o de reducción de la inmigración.

\subsection{DIFÍCIL RETORNO}

Aunque muchos emigrantes se verán obligados a establecerse definitivamente en los países de residencia, el retorno es la más honda y sentida aspiración del emigrante.

Es muy difícil conocer el número de emigrantes que han regresado. Se habla de unos 80.000 anuales a partic del año 1974 .

Según un estudio realizado en Alemania, e1 95,2 por 100 de los emigrantes desea volver a su patria:

- por problemas escolares de sus hijos, el 53 por 100;

- soledad y recuerdos de los suyos, el 38 por $100 ;$

- cansancio de la emigración, el 34 por 100. 
El mismo deseo se puede constatar entre los emigrantes de otros países, debido, sobre todo, a la actual sensación de inseguridad motivada por la crisis económica y las normas discriminatorias que se han ido promulgando.

Al principio de este trabajo se hablaba del derecho a emigrar y del derecho a quedarse. Ahora había que hablar del derecho a permanecer: en el extranjero y del derecho al retono. Por su puesto, incluyendo los medios para decidir libremente la alternativa.

La Constitución Española dice en su artículo 42: «E1 Estado orientará su política hacia el retorno de los trabajadores.»

Existe el peligro de que este principio se quede en una mera declaración de intenciones. A la hora de la verdad, el emigrante se encuentra con enomes dificultades para el retorno.

- Si es diffil encontrar un trabajo en España, más difícil resulta cuando el que busca el empleo se encuentra en Francia, en Alemania... y es un trabajador de cierta edad y con familia. Sería necesario un servicio de infomación y orientación sobre posibilidades y puestos y lugares de trabajo.

- Muchos emigrantes emplearon sus primeros ahorros en la compra de algún piso. Difícilmente coincide el lugar donde compraron el piso con el lugar del posible retomo. A pesar de las normas establecidas que garantizan a los emigrantes la teserva de un cupo de viviendas de protección oficial, así como fórmulas para la concesión de créditos preferentes, los retomados encuentran grandes dificultades para conseguir una vivienda.

-. Los niños encuentran dificultades a la hora del retorno si les falta el suficiente conociniento de la lengua y cultuta maternas. Tienen dificulades para encontrar un puesto escolat y de poco sirve en la práctica la Orden Ministerial (1) que concede a los hijos de los retomados una preferencia en orden a conseguir puestos escolares. No existen convalidaciones de títulos y diplomas de formación profesional.

- Algo hundamental para el emignante retornado que no logra ocupar de inmediato un puesto de trabajo, sería el poder disfrutar del subsidio de paro y de la Seguridad Social. Sin embargo, sólo podrá aspirar a una ayuda econónica del 75 pot 100 del salario mínimo interprofesional y a la Seguridad Social durante seis meses, prorrogable en algunos casos por otros seis, si trae la carta de despido. Si los motivos del retorno son otros (problemas familiares,

(1) Del Ministerio de Eduación y Cencia del 27 de mayo de 1977 «Sobre el insreso de los ragrantes en centros estatales y no estatales》. 
escolarización de los hijos, etc.j, o ha recibido una indemnización superior a tres meses de salario, no tendrá derecho a esas ayudas.

\section{SEGUNDA GENERACION}

\subsection{Qué es la Segunda Generación?}

Llamamos Segunda Generación a los hijos de los emigrantes que han nacido fuera de su país. $Y$ por extensión, a aquellos que han emigrado muy pequeños o al menos durante el tiempo de escolaridad obligatoria.

Dentro del complejo y vasto fenómeno de las migraciones de trabajadores ningún tema acapara hoy la atención como este de la Segunda Generación. Políticos, investigadores, animadores sociales, agentes de la pastoral, tienen que hacer frente, desde hace relativamente pocos años, a un fenómeno nuevo que no formaba parte de la problemática de la enigración inicial.

Todos los países, sin distinción, han tomado conciencia de las dimensiones del problema de los jóvenes, sobre todo en lo concerniente a la escolarización, la formación profesional y ciertos fenómenos que les conciernen. Esta toma de conciencia se debe especialmente a:

- la parte importante de extranjeros de cero a dieciséis años con relación a la población juvenil local de la misma edad;

- el porcentaje considetable (muy grande en los barrios urbanos del extrarradio) de escolares extranjeros en las escuelas de ciclo obligatorio;

- la proporción importante de jóvenes extranjeros de dieciséis a veintiứn años con edad de buscar el primer empleo.

Esta población juvenil presenta características socio-culturales muy diferentes de las de las generaciones de emigrados adultos y no puede ser considerada como una generación que teproduzca la imagen y el rol de sus padres.

La influencia social, cultural, política y económica que tendrá esta población en el interior de cada país europeo y en la formación misma de la Comunidad Europea, constituye hoy todavía un gran interrogante.

Algunos sociólogos prefieren llamar a esta generación, la Generación CERO. El apelativo de Segunda Genetación parece subrayar la telación con los padres y su país de origen y no hace referencia al proceso de aculturación y de socialización vivido por esta generación europea.

En este trabajo se habla en conjunto de la «Segunda Generación Emigrante» española en Europa Occidental, prescindiendo de situaciones 


\section{COMISION EPISCOPAL DE MIGRACION}

diferenciadoras, como por ejemplo, años de estancia en el extranjeto, escolaridad anterior, etc., que no cambian sustancialmente la situación.

\section{2. ¿CUÁNTOS SON?}

Es difícil encontrar estadísticas fiables que permitan conocer con exactitud la situación real.

En el cuadro adjunto se puede ver que de cerca del millón de espa* ñoles (faltan Luxemburgo, Reino Unido y Austria) residentes actualmente en los diversos países europeos, hay alrededor de 250.000 niños menores de dieciséis años (26 por 100). Y unos 350.000 menores de veinticuatro. Es decir, casi cuarro de cada diez españoles emigrantes en Europa no ha cumplido los veinticinco años.

Aunque no existen datos fehacientes publicados, dado el alto número de años de permanencia en el extranjero de la mayor parte de los españoles, podemos afirmar que la mayoría de los niños de doce hasta catorce años han nacido ya en los países de emigración.

\subsection{Características de la Segunda Generactón}

Lo que caracteriza fundamentalmente a esta Segunda Generación es la inseguridad y la falta de identidad. Se debe principalmente a las deficiencias en el sistema educativo y a la constante tensión entre dos naw cionalidades y culturas: la española y la del país de residencia.

Dificultades lingüísticas, dificultades de adaptación socio-cultural a una enseñanza concebida en función y a partir de una cultura extraña, dificultades de los padres para participar en la escuela, antagonismo entre la imagen cultural que trasmite la familia y la identidad cultural que trasmite la escuela.

Todo ello arroja un conjunto de elementos que hacen prever un futuro incietto y un porvenir personal y profesional difícil, tanto si se integran definitivamente en el pafs de «acogida» como si retornan a España.

\subsubsection{Escolarización}

«El grado de instrucción de los niños emigrantes aparece tan insuficiente que es intolerable. El hecho se debe a numerosos factores. Muchos autores sostienen que esa situación hará que los trabajadores migrantes volverán a constituir una segunda generación de trabajadores migrantes, es decir, que los hijos de los emigrantes se quedarán en una condición social inferior a la de sus padres, no sólo en el plano económico, sino 
MIGRACIONES AL EXTRANJERO

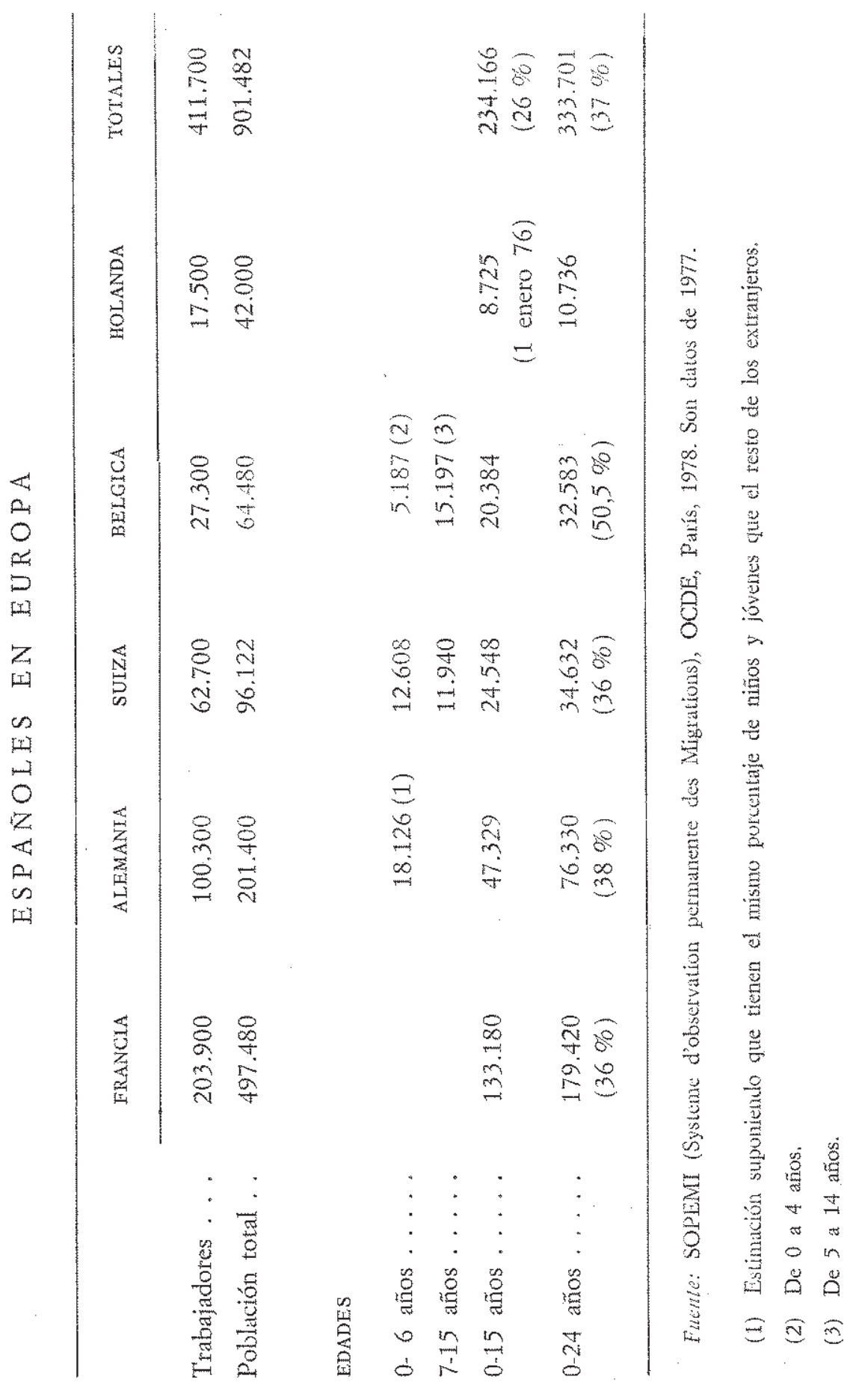


también en el cultural, que serán por así decir, unos desconocidos en la sociedad en la que tantos de ellos han nacido» (1).

Son muchas las causas que obstaculizan el éxito escolar de los hijos de los emigrantes. Algunas de ellas están en el mismo sistema escolar y otras muchas en los condicionamientos del medio familiar y del mismo hecho migratorio.

La emigración es, a veces, el origen de un retraso a la entrada del niño en la escuela y de problemas de tipo linguísticos. La lengua está considerada por todos como un factor determinante para el éxito escolar.

El niño está condicionado en tanto que es hijo de emigrantes. Su medio natural se considera como insuficiente. Además se considera que la teferencia al país de origen es nefasta para la integración y por tanto para el aprendizaje escolar del niño.

Los tininos emigrantes no aprenden correctamente su lengua materna, lo que impide muchas veces el aprendizaje correcto de la lengua de la escuela al faltarles el marco de referencia de la estructura de su propio lenguaje. Por eso se dice que generalmente no son bilingües sino semilingües al no dominar perfectamente la estructua de ninguna de las dos lenguas.

Todos reconocen que en el campo de la educación, las diferencias entre las clases sociales son determinantes. En el caso de los emigrantes, a los inconvenientes relacionados con el origen social se añaden los procedentes de la marcinación social y cultural derivados del hecho migratorio.

Todo ello conduce a un alto porcentaje de retrasos y fracasos, al menos parciales, y a abandonos durante el período de escolaridad obligatoria. También lleva a la oxientación casi obligada de los jóvenes extranjeros hacia profesiones no cualificadas. En definitiva, vuelven a encontrarse en los mismos sectores y las mismas categorias socio-profesionales de sus padres.

En Alemania, pese al aumento en la cuota de obtención de certificados escolates, que llega al máximo en Renania Westfalia con un 63 por 100 queda acuella sin embargo, muy por debajo de la media alemana, un 85 po: $100(2)$.

En Francia y en el curso 1978-79, mientras en el segundo ciclo largo había el curso pasado 6959 niños españoles, eran 9.630 los que cursaban la enseñanza profesional corta y 20.576 los que cursaban el primer ciclo. Había por otra parte 1.321 en escuelas especiales.

(1) «La situation des enfants des Migrants», IV Seminario CIME sobre adapta. ción e integración de los inmigrantes.

(2) «Segunda Generación y Misiones Católicas en Alemania», Dortmund, junio 1979. 


\subsubsection{Escolarización española}

En la totalidad de los países europeos donde residen trabajadotes españoles, existen las llamadas «clases de lengua y cultura españolas», patrocinadas por el Gobierno español.

La situación jurídica de estas clases o unidades escolares varía consin detablemente de un país a otro, o aun dentro del mismo, como varía su funcionamiento (integradas en la escuela nativa o no) y varían las distintas clases de enseñanzas españolas (integrados, contratados, interinos...) que las imparten.

Según datos del I.E.E. en toda Europa existen 828 unidades escolares de EGB y 91 de Bachillerato.

Sin embargo, no parece que asistan a ellas más del 35 por 100 de los niños españoles en edad de frecuentarlas. Eso en EGB. En Bachillerato la cifra debe ser notoriamente inferior.

Si quisiéramos plasmat críticamente la situación de estas escuelas diríamos:

- Suelen tener lugar por la tarde, fuera del horario de la escuela normal (salvo excepciones), lo que supone una sobrecarga para los niños.

- No existe, en general, coordinación con el resto de la enseñanza en las clases ordinarias a las que asiste el niño. $Y$ hay diferencia.

- Tampoco existe, en general, coordinación con los maestros nativos.

- El número de horas por semana oscila entre dos y cinco horas de asistencia libre.

- Es frecuente la existencia de clases unitarias para niños de diferentes edades.

- Muchos de los profesores no están específicamente preparados para esta tarea, ni conocen suficientemente la lengua del país.

- Los métodos de enseñanza pueden diferir de los de los maestros nativos, lo que puede desorientar al niño.

- En general, la escuela española es percibida por los niños como parte integrante, por su situación, de la marginación global que soporta el emigrante (3).

(3) La Segunda Generación Emigrantes Española en Europa, Sanriago Mancho, Madtid 1980. 


\subsubsection{Problemas de identidad}

Los jóvenes emigrantes independientemente de su pasaporte no son simplemente españoles, ni alemanes, ni franceses... Hay en ellos, sin duda, una crisis de identidad. (¿Quién soy? ¿Qué voy a hacer? ¿Dónde voy a vivir?)

Los niños emigrantes se enfrentan a dos culturas diferentes y en conflicto que proponen modelos diversos: la familiar y la escolar.

Hay una dificultad para que los niños se identifiquen con la cultura de sus padres. Esta es una cultura que se presenta en la sociedad en la que viven como inferior, de una minoría marginada.

El niño siente más que sus padres la necesidad de integrarse en la escuela porque el éxito escolar se corresponde con el éxito social, siendo empujados a negar su propia cultura original.

Sin embargo, y a pesar del distanciamiento de su grupo étnico, los jóvenes no llegan a encontrar una nueva identidad. Especialmente cuando por su origen encuentran el rechazo y las dificultades para realizarse tanto en el ámbito escolar como en el del trabajo. Muchas veces oscilan entre el acercamiento a su nacionalidad y su rechazo.

\subsubsection{Otras características}

Los capellanes españoles en Alemania en su reunión de junio del 79 en Dortmund para estudiar los problemas de la Segunda Generación, señalaban las siguientes características, que pueden ser comunes a emigrantes en otras naciones:

- La inseguridad inherente a la condición migrante. No tener nada seguro es una de las situaciones más angustiosas del joven. Esta inseguridad se manifiesta con agudeza cuando el joven termina la escuela y no encuentra una profesión o trabajo conforme a sus deseos.

- El aislamiento que se da por lo general a nivel de grupo, motivado por la diferencia cultural, falta de confianza en los padres, etc., siendo más agudizado en las chicas.

- Una cierta rebeldía frente a posturas autoritarias de los padres.

- Miedo al futuro, a las relaciones, a ser rechazado en casa y en la sociedad.

- Un conflicto generacional agudizado por los siguientes factores:

- los padres en la emigración apenas evolucionan, mientras 
que los hijos se encuentran dentro de un proceso de evolución;

- Las diferencias de ideología y el conocimiento del idioma;

- la petrificación de la familia en su estructura, debido al aislamiento en que vive, respecto a la sociedad en que se encuentra y a la española;

- los padres emigraron movidos por dificultades de tipo económico, mientras que los hijos tienen ya otras metas.

\section{CONSTATACIONES FINALES}

- La emigración y presencia de los españoles en Europa, no es un fenómeno temporal, sino permanente. A pesat de los retornos libres y forzosos, es previsible que muchas familias se quedarán. definitivamente en los países donde emigraron.

Diversos indicios confirman una especie de proceso de estabilización:

- El desarrollo de la población española emigrante no activa (reagrupación familiar, diferente composición demográfica).

- El aumento considerable, aunque restringido en algunos países, de las naturalizaciones.

- Los matrimonios de nacionalidad mixta.

- El proceso de promoción y diversificación socio-profesional de los emigrantes que llevan más años en la emigración.

- La emigración ha beneficiado a España al menos a corto plazo: entrada de divisas, disminución del paro...

$\mathrm{Ha}$ beneficiado a los países de llegada: mano de obra batata... El menos beneficiado ha sido el mismo emigrante a causa de los costes humanos y sociales.

- La emigración, aunque tenga algunos aspectos positivos, es en su conjunto un fenómeno negativo que atenta a la dignidad humana: la misma emigración más o menos forzosa, el desarraigo, la marginación, la carencia de muchos derechos, el futuro incierto de los hijos, la división de las familias, la soledad...

- Los emigrantes se sienten olvidados y marginados en el país donde residen y también por parte de la sociedad española. 
COMISION EPISCOPAL DE MIGRACION

- La llamada Segunda Generación tiene unas características y se enfrenta a tales problemas que merece una atención y un cuidado especial.

- Hay que defender el derecho de los emigrantes tanto al retorno cono a la posibilidad de permanecer en los países donde trabajan.

Ese derecho debe llevar consigo los medios apropiados para una insexción verdadera como ciudadanos de pleno derecho, respetando slz propia identidad personal y colectiva. 